\title{
Correction to: Toxic Metals and Omega-3 Fatty Acids of Bluefin Tuna from Aquaculture: Health Risk and Benefits
}

\author{
Özkan Özden ${ }^{1}$ (D) Nuray Erkan ${ }^{1} \cdot$ Muammer Kaplan $^{2} \cdot$ F. Saadet Karakulak ${ }^{1}$
}

Published online: 1 June 2018

๑) Springer Science+Business Media B.V., part of Springer Nature 2018

\section{Correction to: Expos Health}

https://doi.org/10.1007/s12403-018-0279-9

The original version of this article unfortunately contained mistakes. Under section, 'Estimated Weekly Intake (EWI), the value $150 \mathrm{~g}$ should be corrected as $100 \mathrm{~g}$ in the sentences 'The weekly consumption value for fish...' and 'where WFC is the weekly fish consumption ...'. Likewise under section 'Target Hazard Quotient (THQ),' the data (21.43 g/person/ day) should be (14.26 g/person/day).

The original article can be found online at https://doi.org/10.1007/ s12403-018-0279-9.

\section{Özkan Özden}

ozden@istanbul.edu.tr

1 Department of Fisheries and Seafood Processing Technologies, Faculty of Aquatic Sciences, Istanbul University, Ordu Caddesi No: 8 Laleli, Fatih, Istanbul 34134, Turkey

2 Food Institute, TÜBİTAK Marmara Research Center, Barış Mah. Dr. Zeki Acar Cad. No: 1 P.K. 21, Gebze, Kocaeli 41470, Turkey 